\title{
Assessment of sulfur, calcium and phosphorus in the cuticle covering the cordons of Desportesius invaginatus (Nematoda, Acuariidae) using energy dispersive X-ray microanalysis (EDXMA)
}

\author{
Hewaydah E. Abou Shafeey, Nahla A. Radwan, Amal I. Khalil \\ Department of Zoology, Faculty of Science, University of Tanta, Tanta, Egypt
}

\begin{abstract}
Background: The structure of cordons is a principal characteristic in the identification of acuariid nematodes. The cordons of Desportesius invaginatus are formed of consecutive structurally elaborated plates of variable size and topography. Energy dispersive X-ray microanalysis (EDXMA) is an analytical technique that has been used to evaluate the element composition and crystalline nature of the body surface of cestodes, nematodes and acanthocephalans. It has been also used to measure the concentration of minor elements [sulphur $(\mathrm{S})$, phosphorus $(\mathrm{P})$, calcium $(\mathrm{Ca})$ and potassium $(\mathrm{K})$ ] and trace elements (Fe, $\mathrm{Zn})$.

Objective: The present study was undertaken to investigate the concentration and distribution pattern of some chemical elements, namely: $\mathrm{S}, \mathrm{Ca}$ and $\mathrm{P}$ in the cuticular elaborations of the cordon plates of $D$. invaginatus using dispersive $\mathrm{X}$-ray spectrometry, aiming to supplement information regarding the composition and function of these structures.

Results: Energy dispersive X-ray microanalysis revealed variations in the concentration of $\mathrm{Ca}, \mathrm{S}$ and $\mathrm{P}$ in different regions of the cuticular ridges (tip, middle and base) of the three regions (anterior, middle, posterior) of the cordons of D. invaginatus. In the anterior region of the cordon, $\mathrm{P}$ was the highest in concentration followed by Ca then $\mathrm{S}$; in the middle region, $\mathrm{S}$ exhibited highest concentration followed by $\mathrm{P}$ then $\mathrm{Ca}$; while in the posterior region, $\mathrm{S}$ showed the highest concentration followed by $\mathrm{Ca}$ and $\mathrm{P}$. The study revealed a specific pattern for the distribution and concentration of each element in relation to the region in the cuticular ridges of the cordons. Highest concentration of $\mathrm{Ca}$ and $\mathrm{S}$ was presented in the posterior region, where Ca decreased significantly towards the middle region to reach the lowest levels, then significantly increased again towards the anterior region; while $\mathrm{S}$ reached its lowest concentration in the anterior region, where $\mathrm{P}$ recorded its highest concentration.

Conclusion: The concentration and distribution pattern of $\mathrm{S}, \mathrm{Ca}$, and $\mathrm{P}$ could be related to the anchorage function of the ridges. The high concentration of $\mathrm{S}$ in the base gives flexibility to these structures and facilitates the piercing action of the host tissue; while the accumulation of both $\mathrm{Ca}$ and $\mathrm{P}$ at the tip could result from the polymerization of both elements to give the rigidity and hardness that secure the position of the parasite in the host's tissue and prevent its detachment.
\end{abstract}

Key Words: Calcium, cordons, cuticle, Desportesius invaginatus, EDXMA, nematode, phosphorus, sulphur.

Received: 9 November 2017, Accepted: 26 March 2018

Corresponding Author: Amal I. Khalil, Tel. : 01223194652, E-mail: amal@ametry.com.

ISSN: 1687-7942, Vol. 11, No. 2, August 2018.

\section{INTRODUCTION}

Desportesius invaginatus is an acuariid parasitic nematode that inhabits the gizzard of egrets in Egypt. The structure of cordons is a principal characteristic in the identification of acuariid nematodes ${ }^{[1,2]}$. Cordons are formed of consecutive plates of variable size and topography. The posterior edge of the cuticular plates appears almost smooth in the anterior part of the cordons but is posteriorly elaborated, being ridged in the middle and serrated in the posterior end ${ }^{[3]}$. TEM revealed that these cuticular elaborations enclose opaque to dense material, but did not define the nature of these structures, whether they are spines or just deposited material ${ }^{[3]}$; raising the question, whether spines are integrated in the structure of the ridged and serrated plates of this acuariid nematode?

Energy-dispersive X-ray spectroscopy (EDS, EDX, or $\mathrm{XEDS}$ ), also known as energy dispersive $\mathrm{X}$-ray analysis (EDXA) or energy dispersive X-ray microanalysis
(EDXMA), is an analytical technique used for the elemental analysis or chemical characterization of a sample. It relies on an interaction between X-ray and a sample. Its characterization capabilities are due to the fundamental principle that each element has a unique atomic structure allowing a unique set of peaks on its X-ray spectrum. The technique has been used to evaluate the element composition and crystalline nature of the structures of cestodes $^{[4]}$, nematodes ${ }^{[5-8]}$ and acanthocephalans ${ }^{[9-11]}$. In addition, EDXMA of whole hooks of Echinococcus granulosus protoscoleces demonstrated the presence of $\mathrm{S}$ and trace quantities of $\mathrm{P}$. Their X-ray near-edge absorption spectra resembled those of cystine in feather and hair, and showed $\mathrm{S}$ to be predominantly in the form of disulphide linkages thus differing from vertebrate keratins ${ }^{[4]}$. Other studies revealed that metal concentrations were several thousand times higher in acanthocephalans hooks than in host tissues and that EDXMA would be an excellent method for detecting relatively high concentrations 
$(>1 \%$ wt.) of heavy metals in small amounts of living tissue $^{[9]}$

The present study is undertaken to investigate the chemical nature of the cuticular elaborations of the cordon plates of $D$. invaginatus using dispersive X-ray microanalysis, aiming to reveal whether spine-like structures are incorporated in the cordons. Such information will throw some light on the function of these structures.

\section{MATERIAL AND METHODS}

Adult $D$. invaginatus was collected from the gizzard of Ardeola ibis ibis collected from Gharbia Governorate, Egypt. Nematodes were collected from underneath the lining of the gizzard and washed in normal saline. Specimens were fixed in $70 \%$ ethanol and dehydrated in ascending series of ethanol. Standard methods were followed to prepare each specimen for scanning electron microscopy (SEM) and X-ray microanalysis ${ }^{[12]}$ which included critical point drying (CPD) and mounting on SEM sample mounts using conductive double sided carbon tape. Mounted specimens were coated using two methods, to choose the best suited. In the first, mounted specimens were gold coated for $30 \mathrm{sec}$ (approximate gold coating thickness of $20 \mathrm{~nm}$ ), while in the second method, mounted specimens were charcoal coated using EMITECH K550X sputter coater; and the second method was the best. Samples were examined in a JOELJXA-840A SEM in combination with INCA X-sight X ray analyzer. Samples were imaged at $30 \mathrm{KV}$. EDXMA. Scans were completed for triplicate specimens at the three regions of the cuticular ridges (tip, middle and base) in the three regions of the cordons (anterior, middle and posterior) and in the body cuticle behind the cordons, and at the posterior end where the body cuticle is not elaborated into ridges. The average content of $\mathrm{Ca}, \mathrm{S}$ and $\mathrm{P}$ was recorded.

Statistical analysis: The weight percent (wt.\%) of each chemical element in different regions of the cuticular ridges for each region of the cordons was recorded and analyzed for probability using SPSS computer program. One way ANOVA was used as t test for probability. The mean difference was considered significant at 0.05 level.

\section{RESULTS}

The concentration of three chemical elements namely $\mathrm{S}, \mathrm{Ca}$ and $\mathrm{P}$ in the tip, middle and base of the cuticular ridges (elaborations) of the anterior, middle and posterior regions of the cordons, as well as the anterior and posterior end of the body of $D$. invaginatus are shown in figures 1-5 and tables 1-7.

Variations in concentration of sulphur, calcium and phosphorous in relation to different regions of cordons:

Results presented in table 1 revealed the variations in the concentration of $\mathrm{S}, \mathrm{Ca}$, and $\mathrm{P}$ in the cuticular ridges (elaborations) of the cordons plates of the three regions (anterior, middle and posterior) of the cordons of
D. invaginatus. In the anterior region of the cordons, $\mathrm{P}$ was the highest in concentration followed by $\mathrm{Ca}$ then $\mathrm{S}$. A significant difference $(P=0.000)$ was recorded between the concentration of $\mathrm{S}$ and $\mathrm{P}$ and between the concentration of $\mathrm{Ca}$ and $\mathrm{P}$. The difference between the concentration of $\mathrm{Ca}$ and $\mathrm{S}$ was insignificant $(P=0.573)$. In the middle region of the cordons, $\mathrm{S}$ exhibited the highest concentration followed by $\mathrm{P}$ thenCa. Difference between the concentration of $\mathrm{S}$ and $\mathrm{P}$ and between $\mathrm{Ca}$ and $\mathrm{S}$ was significant $(P=0.000)$. On the other hand, the difference between $\mathrm{Ca}$ and $\mathrm{P}$ concentration was insignificant $(P=0.238)$. In the posterior region of the cordons, $\mathrm{S}$ showed the highest concentration followed by $\mathrm{Ca}$ and $\mathrm{p}$. As with the middle region concentration difference between $\mathrm{S}$ and $\mathrm{P}$, and $\mathrm{Ca}$ and $\mathrm{S}$ was significant $(P=0.000)$; and insignificant $(P=0.096)$ between $\mathrm{Ca}$ and $\mathrm{P}$.

Results presented in table 2 revealed the comparisons of mean difference of EDXA data and the weight percent of $\mathrm{S}, \mathrm{Ca}$ and $\mathrm{P}$ in the cuticular ridges (elaborations) in the three encountered regions (anterior, middle and posterior) of the cordons. Accordingly the highest concentration of $\mathrm{S}$ was in the posterior region of the cordons, decreasing significantly towards the middle region till it reached its lowest concentration in the anterior region. The difference in concentration between the anterior and middle region, anterior and posterior region, and middle and posterior region was statistically significant $(P=0.000)$. A significant difference $(P=0.000)$ was recorded between the concentrations of $\mathrm{S}$ in the three regions of the cordons. The highest concentration of $\mathrm{Ca}$ was in the posterior region of the cordons. The concentration decreased significantly towards the middle region to reach the lowest levels, then significantly increased towards the anterior region to reach levels close to that of the posterior region, but the difference in concentration between the anterior and posterior region was insignificant $(P=0.497)$. A significant difference $(P=0.000)$ was reported between the concentrations of $\mathrm{Ca}$ in the three regions of the cordons. The highest concentration of $\mathrm{P}$ was recorded in the anterior region of the cordons, decreasing sharply towards the middle region reaching its lowest level in the posterior region. A significant difference ( $P=0.000)$ of $\mathrm{P}$ concentration was revealed between the anterior and middle region, as well as between anterior and posterior region. No significant difference $(P=0.190)$ was detected between the middle and posterior region. A significant difference $(\mathrm{P}=0.000)$ was recorded between the concentrations of $\mathrm{P}$ in the three regions of the cordons. The concentration of both $\mathrm{S}$ and $\mathrm{Ca}$ was higher in the posterior than the anterior region, in contrast to that of $\mathrm{P}$ which was higher in the anterior than the posterior region.

\section{Variations in concentration of $\mathrm{S}, \mathrm{Ca}$ and $\mathrm{P}$ in relation to different regions of cordons}

Results presented in tables 3, 4 and 5 reveal variations in concentrations, comparisons of the weight percent, and comparisons of mean difference of EDXMA data for $\mathrm{S}, \mathrm{Ca}$ and $\mathrm{P}$ in different regions of the cuticular ridges (elaborations) (tip middle and base) of the three regions (anterior, middle, posterior) of the cordons. 
Table 3 shows that in the anterior region of the cordons, highest concentration of $(4.26 \mu \mathrm{g} / \mathrm{gm})$ was in the base of the cuticular ridges (elaborations); it decreased gradually towards the middle to reach its lowest value in the tip. In the cuticular ridges (elaborations) of the middle region of the cordon, highest concentration of $\mathrm{S}(29.03 \mu \mathrm{g} / \mathrm{gm})$ was recorded in the tip of the cuticular ridges (elaborations); decreasing gradually towards the middle to reach its lowest value at the base. In the posterior region of the cordons, highest concentration of $\mathrm{S}(46.23 \mu \mathrm{g} / \mathrm{gm})$ was recorded in the base of the cuticular ridges (elaborations); decreasing gradually towards the middle to reach its lowest level in the tip. However, the variations in concentration of $\mathrm{S}$ in the three regions of the spine were statistically insignificant $(P=0.859)$.

In the anterior region of the cordon, highest concentration of $\mathrm{Ca}(4.41 \mu \mathrm{g} / \mathrm{gm})$ was recorded in the tip of cuticular ridges (elaborations), decreasing gradually towards the middle to reach its lowest value in the base. In the middle region of the cordons, highest concentration of $\mathrm{Ca}(1.21 \mu \mathrm{g} / \mathrm{gm})$ was recorded in the base of the cuticular ridges (elaborations), decreasing towards the middle region to reach its lowest concentration, then increase again towards the tip. In the posterior region of the cordons highest concentration of $\mathrm{Ca}(4.79 \mu \mathrm{g} / \mathrm{gm})$ was recorded in the middle of the cuticular ridges (elaborations), decreasing towards the base and tip, where the lowest concentration was recorded in the tip. The difference in concentration of $\mathrm{Ca}$ in the three regions of the cuticular ridges (elaborations) proved insignificant $(P=0.318)$.

The cuticular ridges (elaborations) of the anterior region of the cordons displayed the highest concentration of $\mathrm{P}$ $(14.24 \mu \mathrm{g} / \mathrm{gm})$ at the base; decreasing towards the middle to reach the lowest concentration and then increasing again at the tip. In the middle region of the cordons, cuticular ridges (elaborations) presented highest concentration of $\mathrm{P}$ $(2.57 \mu \mathrm{g} / \mathrm{gm})$ in the middle decreasing towards the tip and base to reach its lowest concentration at the base region. In the posterior region of the cordons, highest concentration of $\mathrm{P}(2.59 \mu \mathrm{g} / \mathrm{gm})$ was recorded in the base of the cuticular ridges (elaborations); decreasing towards the middle region to reach its lowest value then increase again in the tip. The difference in concentration of $\mathrm{P}$ in the three regions of the spine proved to be statistically insignificant $(P=0.396)$.

Tables 4 and 5 show that in the tip, middle and base regions of the cuticular ridges (elaborations), the concentration of $\mathrm{S}$ showed a significant difference between the anterior region and each of the middle $(P=0.000$, $P=0.001, P=0.001$, respectively) and the posterior regions of the cordons ( $P=0.000, P=0.000, P=0.000$, respectively), as well as between the middle and the posterior regions of the cordons ( $P=0.005, P=0.002, P=0.001$, respectively). Tables 4 and 5 also show that in the tip, middle and base regions of the cuticular ridges (elaborations), the concentration of $\mathrm{Ca}$ recorded a significant difference between the middle region and each of the anterior
( $P=0.001, P=0.003, P=0.034$, respectively) and posterior ( $P=0.004, P=0.001, P=0.006$, respectively) regions of the cordons and insignificant $(P=0.179, P=0.363, P=0.187$, respectively) between the anterior and the posterior regions. While the concentration of $\mathrm{P}$ in the tip, middle and base regions of the cuticular ridges (elaborations), recorded a significant difference between the middle region and each of the anterior $(P=0.000, P=0.000$, $P=0.000$, respectively), and the posterior regions of the cordons ( $P=0.000, P=0.000, P=0.000$, respectively), and insignificant ( $P=0.260, P=0.201, P=0.749$, respectively) between the middle and the posterior regions of the cordons.

The body cuticle in the anterior end of $D$. invaginatus behind the cordons shows lower concentrations of $\mathrm{S}, \mathrm{Ca}$ and $\mathrm{P}$ (Table 6) compared with the three reported regions of the cordons, especially in P level(s). Concentrations of the three elements in the cuticle relatively increased towards the posterior end of the worm especially S (Table 6), but were altogether still lower than those reported in different regions of the cordons.

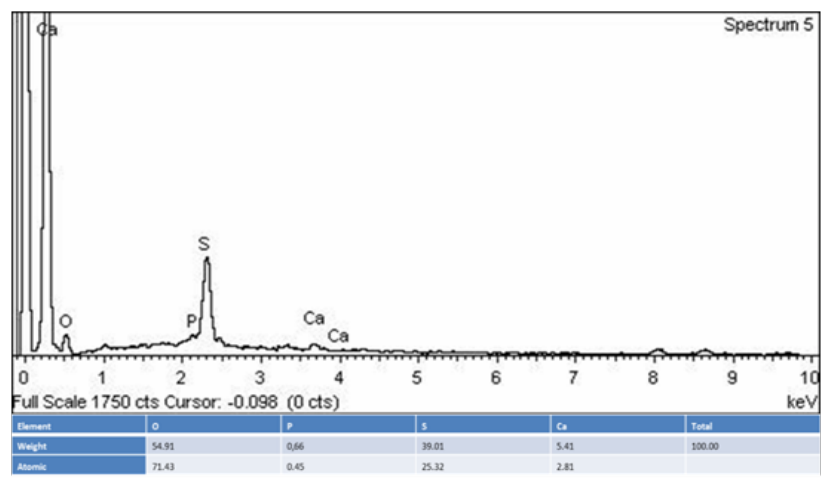

Fig. 1: Chart representing X-ray microanalysis of the middle of the cuticular ridges (elaborations) of the posterior region of the cordons, showing chemical elements at their KV peak with the wt. \% of each element. The chart represents an example of 27 charts covering all cuticular ridges in the three regions of the cordons of $D$. invaginatus. Ca: calcium, O: oxygen, P: phosphorus, S: sulphur.

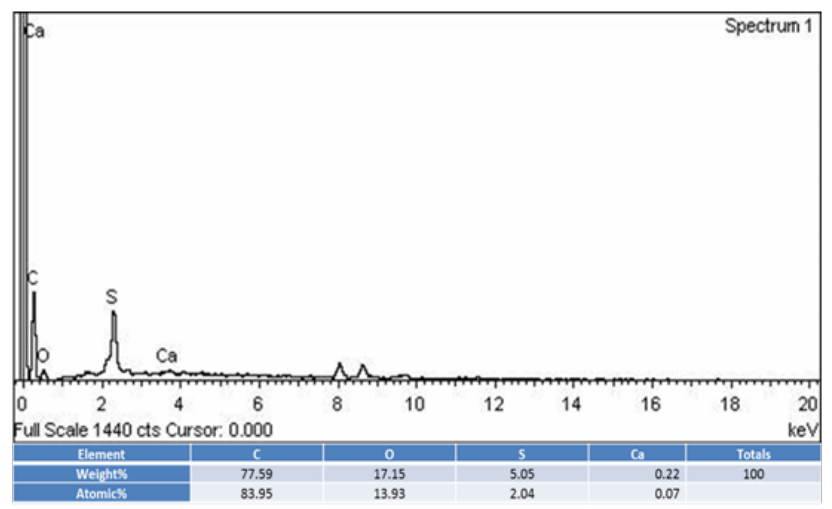

Fig. 2: Chart representing X-ray microanalysis of the cuticle behind the cordons, showing chemical elements at their KV peak with the wt. \% of each element. The chart represents an example of 6 charts covering the cuticle of the body regions behind the cordons and near the posterior end of D.invaginatus. C: carbon, Ca: calcium, O: oxygen, P: phosphorus, S:sulphur 

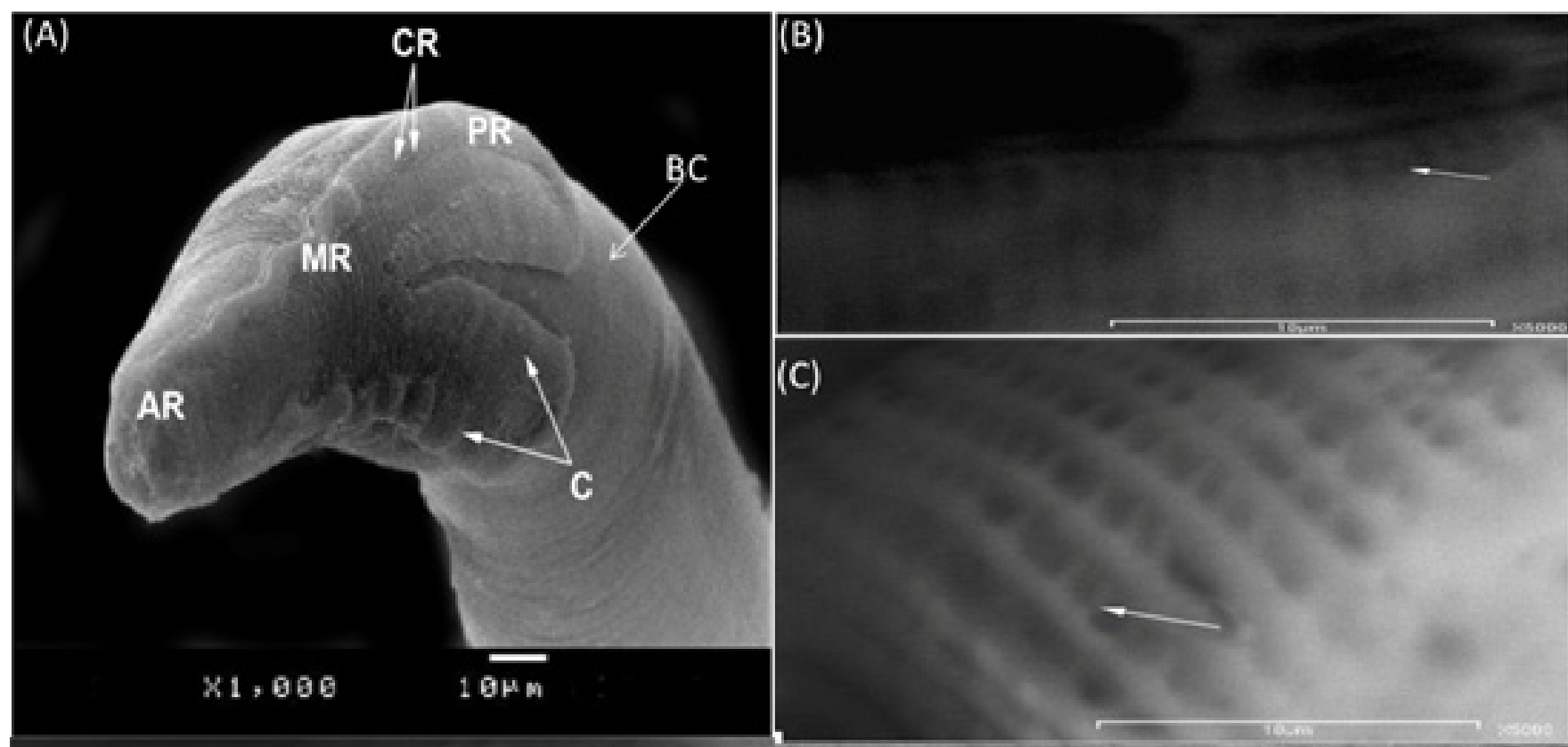

(D)

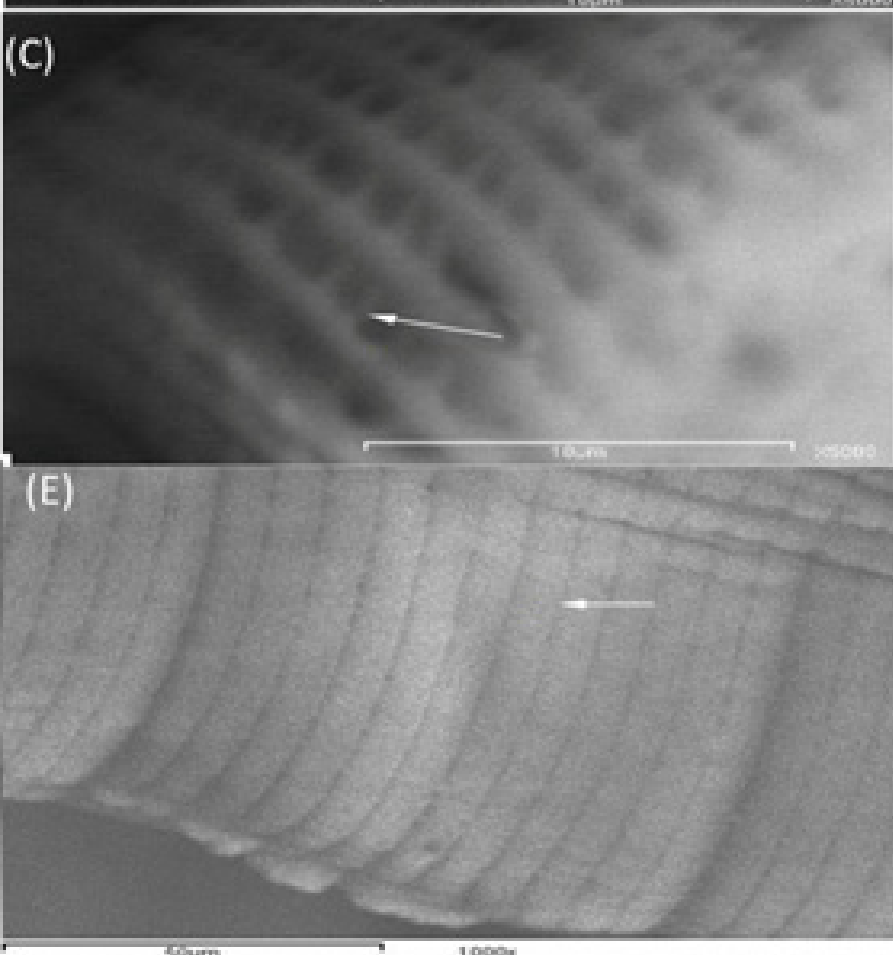

Fig. 3: Scanning electron micrographs of $D$. invaginatus: (A) Dorsolateral view of anterior part of $D$. invaginatus showing the cordons $\mathrm{C}$, (anterior region $\mathrm{AR}$, middle region $\mathrm{MR}$ and posterior region $\mathrm{PR}$ ), cuticular ridges $\mathrm{CR}$ and body cuticle behind the cordons $\mathrm{BC}$, (B) cuticular ridges of the anterior region of the cordons, (C) cuticular ridges (elaborations) of the middle region of the cordons, (D) cuticular ridges (elaborations) of posterior region of the cordons and (E) body cuticle behind the cordons.

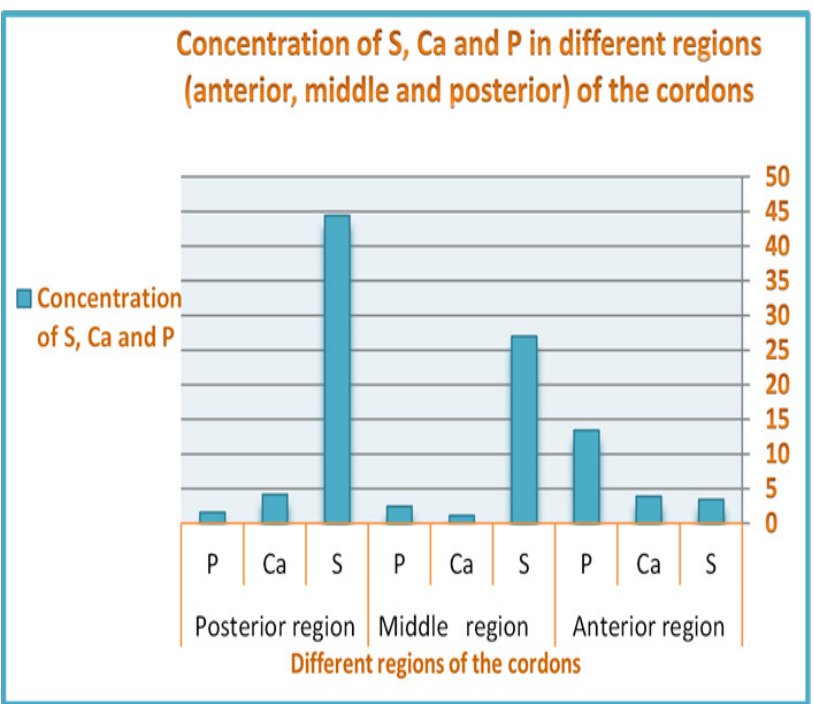

Fig. 4: Concentration percentages of sulphur (S), calcium (Ca) and phosphorus $(\mathrm{P})$ in the anterior, middle and posterior regions of the cordons of $D$. invaginatus.

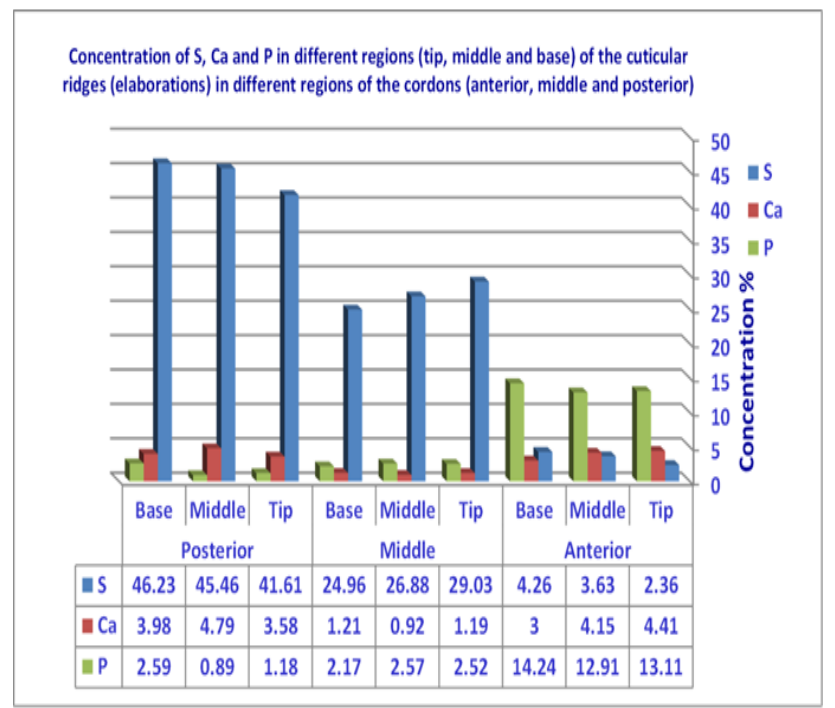

Fig. 5: Concentrations of sulphur $(\mathrm{S})$, calcium $(\mathrm{Ca})$, and phosphorus $(\mathrm{P})$ in different regions of the cuticular ridges (tip, middle and base) (elaborations) in the three regions of the cordons of $D$. invaginatus 
Table 1: Concentrations of sulphur (S), calcium $(\mathrm{Ca})$ and phosphorus $(\mathrm{P})$ and multiple comparisons of $P$ value of EDXA data between sulphur $(\mathrm{S})$ and each of calcium $(\mathrm{Ca})$ and phosphorus $(\mathrm{P})$ in the cuticular ridges (elaborations) of the three regions of the cordons (anterior, middle and posterior)

\begin{tabular}{|c|c|c|c|c|c|c|c|c|c|}
\hline \multirow{3}{*}{$\begin{array}{l}\text { Cordons } \\
\text { region }\end{array}$} & \multirow{3}{*}{ Element } & \multirow{3}{*}{ Mean \pm SD } & \multicolumn{7}{|c|}{ Statistical analysis $(P=$ value $)$} \\
\hline & & & \multirow{2}{*}{$\begin{array}{l}\text { For } \\
\text { region }\end{array}$} & \multicolumn{3}{|c|}{$S$ versus $C a$ and $P$} & \multicolumn{3}{|c|}{$P$ versus $\mathbf{C a}$} \\
\hline & & & & Ant. & Mid. & Post. & Ant. & Mid. & Post \\
\hline \multirow{3}{*}{$\begin{array}{l}\text { Anterior } \\
\text { region }\end{array}$} & $\mathrm{S}$ & $3.42 \pm 1.61$ & \multirow{3}{*}{$0.000^{*}$} & & & & & & \\
\hline & $\mathrm{Ca}$ & $3.85 \pm 0.82$ & & 0.573 & & & $0.000^{*}$ & & \\
\hline & $\mathrm{P}$ & $13.42 \pm 2.11$ & & $0.000 *$ & & & & & \\
\hline \multirow{3}{*}{$\begin{array}{l}\text { Middle } \\
\text { region }\end{array}$} & $\mathrm{S}$ & $26.95 \pm 3.88$ & \multirow{3}{*}{$0.000 *$} & & & & & & \\
\hline & $\mathrm{Ca}$ & $1.10 \pm 0.89$ & & & $0.000^{*}$ & & & 0.238 & \\
\hline & $\mathrm{P}$ & $2.42 \pm 0.41$ & & & $0.000^{*}$ & & & & \\
\hline \multirow{3}{*}{$\begin{array}{l}\text { Posterior } \\
\text { region }\end{array}$} & $\mathrm{S}$ & $44.43 \pm 5.30$ & \multirow{3}{*}{$0.000^{*}$} & & & & & & \\
\hline & $\mathrm{Ca}$ & $4.12 \pm 0.75$ & & & & $0.000^{*}$ & & & 0.096 \\
\hline & $\mathrm{P}$ & $1.55 \pm 1.00$ & & & & $0.000^{*}$ & & & \\
\hline
\end{tabular}

*The mean difference is significant at 0.05 level

Table 2: Multiple comparisons of the mean difference ( $P$ value) of EDXA data of sulphur $(\mathrm{S})$, calcium $(\mathrm{Ca})$, and phosphorus $(\mathrm{P})$, the mean weight percent (wt.\%) and $P$ value of the three elements in the cuticular ridges of the three regions (anterior, middle and posterior) of the cordons

\begin{tabular}{|c|c|c|c|c|c|c|c|c|c|}
\hline \multirow{3}{*}{ Element } & \multirow{3}{*}{$\begin{array}{l}\text { Cordons } \\
\text { region }\end{array}$} & \multirow{3}{*}{ Mean \pm SD } & \multicolumn{7}{|c|}{ Statistical analysis $(P=$ value $)$} \\
\hline & & & \multirow{2}{*}{$\begin{array}{c}\text { For } \\
\text { Element }\end{array}$} & \multicolumn{3}{|c|}{ Ant. versus Mid. \& Post. } & \multicolumn{3}{|c|}{ Mid. versus Post } \\
\hline & & & & $\mathbf{S}$ & $\mathbf{C a}$ & $\mathbf{P}$ & $\mathbf{S}$ & $\mathbf{C a}$ & $\mathbf{P}$ \\
\hline \multirow{4}{*}{$\mathbf{S}$} & Ant. & $3.42 \pm 1.61$ & \multirow{4}{*}{$0.000^{*}$} & & & & & & \\
\hline & Mid. & $26.95 \pm 3.88$ & & $0.000 *$ & & & & & \\
\hline & Post. & $44.43 \pm 5.30$ & & $0.000 *$ & & & $0.000 *$ & & \\
\hline & Total & $24.94 \pm 17.5$ & & & & & & & \\
\hline \multirow{4}{*}{ Ca } & Ant. & $3.85 \pm 0.82$ & \multirow{4}{*}{$0.000^{*}$} & & & & & & \\
\hline & Mid. & $1.10 \pm 0.89$ & & & $0.000 *$ & & & & \\
\hline & Post. & $4.12 \pm 0.75$ & & & 0.497 & & $0.000 *$ & & \\
\hline & Total & $3.02 \pm 1.60$ & & & & & & & \\
\hline \multirow{4}{*}{$\mathbf{P}$} & Ant. & $13.42 \pm 2.11$ & \multirow{4}{*}{$0.000 *$} & & & & & & \\
\hline & Mid. & $2.42 \pm 0.41$ & & & & $0.000^{*}$ & & & \\
\hline & Post. & $1.55 \pm 1.00$ & & & & $0.000 *$ & & & 0.190 \\
\hline & Total & $5.80 \pm 5.66$ & & & & & & & \\
\hline
\end{tabular}

*The mean difference is significant at 0.05 level 
Table 3: Statistical analysis of the mean weight percent (wt.\%) and ( $P$ value) of sulphur (S),calcium $(\mathrm{Ca})$ and phosphorus $(\mathrm{P})$ in three regions (tip, middle and base) of cuticular ridges (elaborations) in the three regions of the cordons (anterior, middle and posterior)

\begin{tabular}{|c|c|c|c|c|c|}
\hline \multirow{3}{*}{ Element } & \multirow{3}{*}{$\begin{array}{l}\text { Cuticular } \\
\text { ridges }\end{array}$} & \multicolumn{3}{|c|}{ Cordons regions } & \multirow{3}{*}{$\begin{array}{c}\text { Statistical analysis } \\
\text { t test }(P \text { value }) \text { Exac } \\
\text { F test }(P \text { value })\end{array}$} \\
\hline & & Anterior & Middle & Posterior & \\
\hline & & $\operatorname{Mean} \pm$ SD & $\operatorname{Mean} \pm$ SD & $\operatorname{Mean} \pm$ SD & \\
\hline \multirow{4}{*}{$\mathbf{S}$} & Tip & $2.36 \pm 2.05$ & $29.03 \pm 4.52$ & $41.61 \pm 3.70$ & \multirow{3}{*}{$\begin{array}{c}0.152 \\
(0.859)\end{array}$} \\
\hline & Mid. & $3.63 \pm 0.93$ & $26.88 \pm 2.69$ & $45.46 \pm 7.36$ & \\
\hline & Base & $4.26 \pm 1.60$ & $24.96 \pm 4.48$ & $46.23 \pm 5.10$ & \\
\hline & Exact F test & & & & $230.05(0.000 *)$ \\
\hline \multirow{4}{*}{$\mathbf{C a}$} & Tip & $4.41 \pm 0.86$ & $1.19 \pm 0.16$ & $3.58 \pm 0.75$ & \multirow{3}{*}{$\begin{array}{c}1.223 \\
(0.318)\end{array}$} \\
\hline & Mid. & $4.15 \pm 0.27$ & $0.92 \pm 1.15$ & $4.79 \pm 0.72$ & \\
\hline & Base & $3 \pm 0.43$ & $1.21 \pm 1.32$ & $3.98 \pm 0.16$ & \\
\hline & Exact F test & & & & $43.429(0.000 *)$ \\
\hline \multirow{4}{*}{$\mathbf{P}$} & Tip & $13.11 \pm 2.13$ & $2.52 \pm 0.66$ & $1.18 \pm 0.54$ & \multirow{3}{*}{$\begin{array}{c}0.98 \\
(0.396)\end{array}$} \\
\hline & Mid. & $12.91 \pm 2.45$ & $2.57 \pm 0.23$ & $0.89 \pm 0.27$ & \\
\hline & Base & $14.24 \pm 2.38$ & $2.17 \pm 0.20$ & $2.59 \pm 1.07$ & \\
\hline & Exact $F$ test & & & & $194.294\left(0.000^{*}\right)$ \\
\hline
\end{tabular}

*The mean difference is significant at 0.05 level 
Desportesius invaginatus cuticle EDXMA Abou Shafeey et al.

Table 4: The mean weight percent (wt.\%) of sulphur (S), calcium (Ca) and phosphorus (P) in the tip, middle and base of the cuticular ridges (elaborations) of the different regions of the cordons

\begin{tabular}{|c|c|c|c|c|c|}
\hline Cuticular ridges & Element & Cordons regions & No. & Mean \pm SD & Statistical analysis $P$ value \\
\hline \multirow{12}{*}{ Tip } & \multirow{4}{*}{$\mathbf{S}$} & Ant. & 3 & $2.36 \pm 2.05$ & \multirow{4}{*}{$0.000^{*}$} \\
\hline & & Mid. & 3 & $29.03 \pm 4.52$ & \\
\hline & & Post. & 3 & $41.61 \pm 3.70$ & \\
\hline & & Total & 9 & $24.33 \pm 17.63$ & \\
\hline & \multirow{4}{*}{$\mathrm{Ca}$} & Ant. & 3 & $4.41 \pm 0.86$ & \multirow{4}{*}{$0.003 *$} \\
\hline & & Mid. & 3 & $1.19 \pm 0.16$ & \\
\hline & & Post. & 3 & $3.58 \pm 0.75$ & \\
\hline & & Total & 9 & $3.06 \pm 1.56$ & \\
\hline & \multirow{4}{*}{$\mathbf{P}$} & Ant. & 3 & $13.11 \pm 2.13$ & \multirow{4}{*}{$0.000^{*}$} \\
\hline & & Mid. & 3 & $2.52 \pm 0.66$ & \\
\hline & & Post. & 3 & $1.18 \pm 0.54$ & \\
\hline & & Total & 9 & $5.61 \pm 5.78$ & \\
\hline \multirow{12}{*}{ Middle } & \multirow{4}{*}{$\mathbf{S}$} & Ant. & 3 & $3.63 \pm 0.93$ & \multirow{4}{*}{$0.000^{*}$} \\
\hline & & Mid. & 3 & $26.88 \pm 2.69$ & \\
\hline & & Post. & 3 & $45.46 \pm 7.36$ & \\
\hline & & Total & 9 & $25.33 \pm 18.57$ & \\
\hline & \multirow{4}{*}{$\mathrm{Ca}$} & Ant. & 3 & $4.15 \pm 0.27$ & \multirow{4}{*}{$0.002 *$} \\
\hline & & Mid. & 3 & $0.92 \pm 1.15$ & \\
\hline & & Post. & 3 & $4.79 \pm 0.72$ & \\
\hline & & Total & 9 & $3.29 \pm 1.92$ & \\
\hline & \multirow{4}{*}{$\mathbf{P}$} & Ant. & 3 & $12.91 \pm 2.45$ & \multirow{4}{*}{$0.000^{*}$} \\
\hline & & Mid. & 3 & $2.57 \pm 0.23$ & \\
\hline & & Post. & 3 & $0.89 \pm 0.27$ & \\
\hline & & Total & 9 & $5.46 \pm 5.77$ & \\
\hline \multirow{12}{*}{ Base } & \multirow{4}{*}{$\mathbf{S}$} & Ant. & 3 & $4.26 \pm 1.60$ & \multirow{4}{*}{$0.000^{*}$} \\
\hline & & Mid. & 3 & $24.96 \pm 4.48$ & \\
\hline & & Post. & 3 & $46.23 \pm 5.10$ & \\
\hline & & Total & 9 & $25.15 \pm 18.50$ & \\
\hline & \multirow{4}{*}{$\mathrm{Ca}$} & Ant. & 3 & $3.00 \pm 0.43$ & \multirow{4}{*}{$0.015^{*}$} \\
\hline & & Mid. & 3 & $1.21 \pm 1.32$ & \\
\hline & & Post. & 3 & $3.98 \pm 0.16$ & \\
\hline & & Total & 9 & $2.73 \pm 1.40$ & \\
\hline & \multirow{4}{*}{$\mathbf{P}$} & Ant. & 3 & $14.24 \pm 2.38$ & \multirow{4}{*}{$0.000 *$} \\
\hline & & Mid. & 3 & $2.17 \pm 0.20$ & \\
\hline & & Post. & 3 & $2.59 \pm 1.07$ & \\
\hline & & Total & 9 & $6.33 \pm 6.08$ & \\
\hline
\end{tabular}

*The mean difference is significant at 0.05 level 
Table 5: Statistical analysis of multiple comparisons ( $P$ value) of EDXMA data for sulphur $(\mathrm{S})$, calcium $(\mathrm{Ca})$ and phosphorus $(\mathrm{P})$ between the three regions (tip, middle and base) of cuticular ridges (elaborations) in different cordons regions (anterior, middle and posterior)

\begin{tabular}{|c|c|c|c|c|c|c|}
\hline & \multicolumn{2}{|c|}{$\mathbf{S}$} & \multicolumn{2}{|c|}{$\mathbf{C a}$} & \multicolumn{2}{|c|}{$\mathbf{P}$} \\
\hline & Ant. region & Mid. region & Ant. region & Mid. region & Ant. region & Mid. region \\
\hline \multicolumn{7}{|c|}{ Tip of cuticular ridges } \\
\hline Mid. region & 0000 & & 0.001 & & 0.000 & \\
\hline Post. region & 0.000 & 0.005 & 0.179 & 0.004 & 0.000 & 0.260 \\
\hline \multicolumn{7}{|c|}{ Middle of cuticular ridges } \\
\hline Mid. region & 0.001 & & 0.003 & & 0.000 & \\
\hline Post. region & 0.000 & 0.002 & 0.363 & 0.001 & 0.000 & 0.201 \\
\hline \multicolumn{7}{|c|}{ Base of cuticular ridges } \\
\hline Mid. region & 0.001 & & 0.034 & & 0.000 & \\
\hline Post. region & 0.000 & 0.001 & 0.187 & 0.006 & 0.000 & 0.749 \\
\hline
\end{tabular}

*The mean difference is significant at 0.05 level

Table 6: Concentrations of sulphur $(\mathrm{S})$, calcium $(\mathrm{Ca})$ and phosphorus $(\mathrm{P})$ in the body cuticle of the anterior end behind the cordons and posterior end

\begin{tabular}{lcc}
\hline \multicolumn{1}{c}{ Body region } & Element & Mean \pm SD \\
\hline & $\mathbf{S}$ & $3.40 \pm 0.23$ \\
\cline { 2 - 3 } Anterior end of the body behind the cordons & $\mathbf{C a}$ & $0.40 \pm 0.08$ \\
\hline & $\mathbf{P}$ & $0.25 \pm 0.00$ \\
\hline \multirow{2}{*}{ Posterior end of the body } & $\mathbf{S}$ & $8.90 \pm 1.2$ \\
\cline { 2 - 3 } & $\mathbf{C a}$ & $1.39 \pm 1.00$ \\
\hline
\end{tabular}




\section{DISCUSSION}

The present study questions the nature of the cuticular ridges (elaborations) of the cordons of $D$. invaginatus. In the following discussion, the distribution and content of the three elements in these elaborations is compared with that in the cuticle behind the cordons, where the cuticle is not elaborated into spine-like structures. Comparison will also be done in relation to spines, hooks and other hard structures in invertebrates and vertebrates. The ultimate goal is to reveal whether the cuticular ridges incorporate hard material that can be referred to as spines or not.

Sulphur, $\mathrm{Ca}$ and $\mathrm{P}$ are major elements in biological molecules of all representatives of the animal kingdom and previous studies ${ }^{[7,8,9,15,28,30]}$ revealed that they are associated with the development and function of helminth hooks and spines (Table 7) ${ }^{[14,15,28,29,30-33]}$.

Table 7: Concentrations of sulphur (S), calcium (Ca) and phosphorus $(\mathrm{P})$ in different epidermal derivatives through the kingdom Animalia.

\begin{tabular}{|c|c|c|c|c|c|}
\hline \multirow{2}{*}{ Species } & \multirow{2}{*}{ Region } & \multicolumn{3}{|c|}{ Element } & \multirow{2}{*}{ Reference } \\
\hline & & $\mathbf{S}$ & $\mathbf{C a}$ & $\mathbf{P}$ & \\
\hline \multirow[t]{3}{*}{ Human } & Finger nail & - & $1.06 \mu \mathrm{g} / \mathrm{gm}$ & - & \multirow{3}{*}{28} \\
\hline & & $4.18 \%$ & $0.52 \%$ & $0.02 \%$ & \\
\hline & Hair & - & $1.15 \mu \mathrm{g} / \mathrm{gm}$ & - & \\
\hline Adult cicada Magicicada spp & Exoskeleton & $0.090 \%$ & $0.391 \%$ & $0.633 \%$ & 29 \\
\hline Trilobite & Exoskeleton & - & $35.18 \pm 2.73 \%$ & - & 30 \\
\hline Shrimp & $\begin{array}{l}\text { Shell } \\
\text { (Exoskeleton) }\end{array}$ & - & $46.962 \%$ & - & 31 \\
\hline Deer & Antler & - & $\begin{array}{c}127.83 \pm 12.75 \\
\mathrm{mg} / \mathrm{gm}\end{array}$ & $\begin{array}{c}76.75 \pm 12.74 \\
\mathrm{mg} / \mathrm{gm}\end{array}$ & 32 \\
\hline Cray Fish & Skin & - & $0.079 \%$ & $0.02 \%$ & \multirow{3}{*}{33} \\
\hline Croacker Fish & Skin & - & $0.42 \%$ & $0.09 \%$ & \\
\hline Mackerel Fish & Skin & - & $0.6 \%$ & $0.09 \%$ & \\
\hline \multicolumn{6}{|l|}{ Acanthocephalans } \\
\hline Rhadinorhynchus ornatus & \multirow{4}{*}{ Proboscis hooks } & $13.30 \%$ & $4.50 \%$ & $3.40 \%$ & \multirow{5}{*}{15} \\
\hline Neoechinorhynchus idahoensis & & $5.10 \%$ & $1.15 \%$ & $1.24 \%$ & \\
\hline Acanthocephalus dirus & & $4.90 \%$ & $12.07 \%$ & $6.70 \%$ & \\
\hline Sphaerirostris $s p$ & & $3.29 \%$ & $13.80 \%$ & $9.10 \%$ & \\
\hline Rhadinorhynchus ornatus & Body spines & $6.20 \%$ & $0.90 \%$ & $0.83 \%$ & \\
\hline \multicolumn{6}{|l|}{ Digenetic trematodes } \\
\hline Fasciola hepatica & Tegumental spine & $2.01 \%$ & $2.7 \%$ & $0.28 \%$ & \multirow{3}{*}{14} \\
\hline Schistosoma heamatobium & around attachement & $0.25 \%$ & $0.06 \%$ & $0.39 \%$ & \\
\hline Cyndoplostimum azimi & & $0.47 \%$ & $0.04 \%$ & $0.40 \%$ & \\
\hline Nematode & Cuticular cordons & & & & \multirow{6}{*}{ Present study } \\
\hline \multirow[t]{5}{*}{ Desportesius invaginatus } & Anterior region & $3.42 \%$ & $3.85 \%$ & $13.42 \%$ & \\
\hline & Middle region & $26.95 \%$ & $1.10 \%$ & $2.42 \%$ & \\
\hline & Posterior region & $44.43 \%$ & $4.12 \%$ & $1.55 \%$ & \\
\hline & $\begin{array}{l}\text { Body cuticle behind } \\
\text { cordons }\end{array}$ & $3.40 \%$ & $0.40 \%$ & $0.25 \%$ & \\
\hline & $\begin{array}{l}\text { Body cuticle in } \\
\text { posterior end of body }\end{array}$ & $8.90 \%$ & $1.39 \%$ & $0.70 \%$ & \\
\hline
\end{tabular}


Phosphorous supports the formation of bones and teeth along with $\mathrm{Ca}$; it gives the hardness, strength and rigidity to resist compressive forces. Carbon and $\mathrm{S}$ are main constituents of keratin which is the building component of hair, horns, hooves, beaks, shells, nails, claws ... etc. Studies suggested correlation between the distribution pattern and concentration of the three elements in different epidermal and tegmental structures with the possible functional morphology of each ${ }^{[13-16]}$.

Fraser et al. ${ }^{[17]}$ defined keratin as insoluble cysteinecontaining protein, often showing a microfibrillar substructure and it is the presence of the di-amino acid cysteine, which is the sulphur containing amino acid, that distinguish it from other structural proteins.

Histochemical analyses of cestode hooks demonstrated the presence of disulphide and sulphydryl groups, suggesting that the outer cortex is richer in disulphide linkage than the inner core ${ }^{[18-22]}$. Smith and Richards ${ }^{[4]}$ demonstrated the concentration of both $\mathrm{S}$ and $\mathrm{P}$ in the protoscolex hooks of E. granulosus and reported that the presence of $\mathrm{S}$ in the oxited state is more in the amino acid cysteine than cystine and suggested a strong similarity between $E$. granulosus hooks and feather and hair keratin, with sulphur present as disulphide bridges rather than free thiol groups. The authors discussed the validity of using the term keratin to refer to cestode hook material.

Energy-dispersive X-ray analysis (EDXA) of the freeliving nematode Xiphinema vuittenezi ${ }^{[5]}$, Ascaris suum ${ }^{[6]}$ and the marine nematode Tripyloides marinus ${ }^{[8]}$ revealed the presence of $\mathrm{S}, \mathrm{Ca}$ and $\mathrm{P}$ in the epidermis and cuticle, as well as muscle, hypodermis and intestinal epithelial cells of these nematodes. Similarly the present study demonstrated the presence of $\mathrm{S}, \mathrm{Ca}$ and $\mathrm{P}$ in the cuticle, regardless of the presence of the elaborated cordons.

Heckmann et al. ${ }^{[15]}$ revealed a proportional relation between the level of $\mathrm{S}$ and the thickness of both the cortex and fibrillar medulla in Rhadinorhynchus ornatus (Acanthocephala) proboscis hooks. They related the high $\mathrm{S}$ content at the tip of the hook and along the edges to the probability of polymerization into a complex protein with disulfide bonds, that have an important role in the stability of the protein formed between the thiol groups of the amino acids. Also that cysteine and cystine are probably the main sulphur containing amino acids in the hooks of Acanthocephala. They related the high level of phosphorus at the hook base to the alkaline phosphatase activity of this region. The authors also correlated the variations in the distribution pattern of $\mathrm{Ca}$ and $\mathrm{P}$ of the anterior hooks versus the posterior hooks, to the anchorage mechanism within the host tissue and how much rigidity of the posterior hooks is needed over the anterior ones.
Radwan et al. ${ }^{[14]}$ linked the differences in concentration and distribution pattern of $\mathrm{S}, \mathrm{Ca}$ and $\mathrm{P}$ in different digenean tegmental spines to the habitat richness in these elements, and the ability of these digeneans to metabolize and make use of these elements. The authors suggested that high $\mathrm{Ca}$ and $\mathrm{P}$ concentration in the spine tip makes for the low $\mathrm{S}$ and might represent components of calcium phosphate that give the spine rigidity; while the high $\mathrm{S}$ concentration in the spine body gives rigidity and makes for the decreasing $\mathrm{Ca}$ and $\mathrm{P}$ content in these parts of the spine.

The present results showed variations in the concentrations of $\mathrm{S}, \mathrm{Ca}$ and $\mathrm{P}$ in relation to different cordon regions. The highest concentration of $\mathrm{S}$ and $\mathrm{Ca}$ was reported in the posterior region of cordons where $\mathrm{Ca}$ decreased gradually till the middle then increased again towards the anterior region, while $\mathrm{S}$ steadily decreased towards the anterior region. On the other hand, $\mathrm{P}$ had its highest concentration in the anterior region and decreased posteriorly. The distribution pattern of the three elements throughout the entire cordons may support the probable functions of the cordons where the worm needs hardness of the anterior region for grasping food particles, elasticity in the middle region for passing them towards the buccal cavity ${ }^{[23]}$ and rigidity of the posterior part to support its anchorage function.

In the present study, the high concentration of $\mathrm{Ca}$ in the tip of the cordon ridges (the spine-like structures), of both anterior and posterior regions of the cordons, may account for the rigidity needed for effective anchorage, while the high concentration of $\mathrm{S}$ in the base of the cordon ridges of both anterior and posterior regions of the cordons, may support flexibility required for movement at the base of the cordons. This pattern of distribution is similar to that reported in acanthocephalan hooks ${ }^{[15]}$ where the high $\mathrm{Ca}$ and $\mathrm{P}$ content at the tip was correlated with formation of a rigid $\mathrm{Ca}$ phosphate apatite similar to the enamel of mammalian teeth with disulphide bonds (cysteine) enhancing the structure.

To validate the nature of the cuticular elaborations of the cordons and define whether these structures incorporate true spines, the present findings were compared with the $\mathrm{S}$, $\mathrm{Ca}$ and $\mathrm{P}$ content in different hard structures in invertebrates and vertebrates (Table 7).

In the anterior part of the cordons, $\mathrm{S}$ content was almost the same as the body cuticle behind the cordons but higher than in the posterior end of the worm. However, in the middle and posterior regions of the cordons, S concentration was higher than the body cuticle and also higher than the human nail, invertebrate exoskeleton, acanthocephalan hooks and digenean spines. On the other hand, Ca composition was slightly higher than the cuticle behind the cordons and in the posterior part of the body and much higher than digenean and acanthocephalan 
spines, Neoechinorhyncus hooks, human nail, invertebrate exoskeleton and fish skin. Phosphorus content was higher in the cordons particularly the anterior region than the cuticle behind the cordons and the posterior end of the worm, and also higher than invertebrate exoskeleton, digenean spines, acanthocephalan spines and hooks and human hair.

In answer to the question whether the cuticular elaborations incorporate spines, the present study revealed that $\mathrm{S}, \mathrm{Ca}$ and $\mathrm{P}$ were found at differentially higher concentration in the cuticular elaborations than digenean and acanthocephalan spines and hooks. These findings point to the strong possibility that these elaborations incorporate spines comparable with digenean and acanthocephalan spines and that these structures function in anchorage and feeding by abrading the host mucosa.

The considerably higher element composition in the cuticle behind the cordons and in the posterior part of the body is explainable because these worms need rigid cuticle to protect the body against the mechanical pressure of the gizzard of Ardeola ibis ibis.

Using TEM, Abou Shafey ${ }^{[3]}$ illustrated that the cordons in D. invaginatus are elaborated into spine-like cuticular ridges that probably integrate hard material and that these elaborations are extensions of the middle cuticular layers, with the vesicular sub-layer replaced by a denser matrix which may be protienaceous, or may contain deposits of unknown nature and that the matrix is probably synthesized and mobilized by the polymorphic bodies at the base of the cordon. When these findings are correlated with the present finding, the dense matrix may correspond to spines. In accordance with this assumption, Kennedy et $a l^{[23]}$ studying the fine structure of the cordons of Echinuria uncinata (Nematode: Spirurida) assumed that the dense material of the cordons is comparable with the cuticular spines and suggested that both the cordons and spines may have the same internal structure being more electron dense than the rest of the cuticle.

The present study using EDXMA to investigate sulfur, calcium and phosphorus content in the cuticle covering the cordons of $D$. invaginatus, defined that the cordon incorporates spines comparable with that of other helminth.

The present finding of spine-like structures incorporated within the cordons of $D$. invaginatus opens the question whether all or some acuariid possess such structures? and whether structural variations of these spines are taxonomically valid? Scientists disagreed on the nature of the cuticular ridges of the cordons of accuarids. Kennedy et $a .^{[23]}$ described the cordons of Echinuria uncinata as formed of plates with superficial teeth-like structures in addition to their body spines and reported that both the cordons and the body spines are more electron dense than the body cuticle and have the same fine structure. Although, Wong and Anderson ${ }^{[24]}$ revised the genus Desportesius and published a key to species, they did not refer to the detailed cordon structure and whether there are spines or ridges on the cordons. Mutafchiev and Georgiev ${ }^{[25]}$ described the cordons of Desportesius brevicoudatus as consisting of cuticular plates with serrated posterior rim bearing 10-12 spines, while Varjabedian ${ }^{[26]}$ described the cordons of $D$. invaginatus as having transverse rows of minute spines. Finally in the archival volume of the key to nematodes parasites of vertebrates, Anderson et al. ${ }^{[27]}$ defined the genus Desportesius as having cordons expanded posteriorly often with spines.

\section{CONCLUSION}

Further studies are needed to reveal the fine structure of spines of different acuariid and to evaluate the taxonomic validity of these structures and the extent of inter and intraspecific structural variations.

Author contribution: HE Abu Shafeey performed the research, contributed and share in analyzing the data, wrote the paper and prepared the search for publication. NA Radwan contributed in analyzing the data. AI Khalil conceived and designed the research and discussed the results.

Conflict of interest: There is no conflict of interest.

\section{Financial support and sponsorship: Nil}

\section{REFERENCES}

1. Chabaud AG, Petter AJ. Essai de classification des nematodes Acuariidae. Ann Parasitol Hum Comp 1959; 34: 33-49.

2. Mawson PM. Some Acuariinae (Nematoda) from Australian birds. Trans Proc Roy Soc South Australia 1982; 106 (1): 19-30.

3. Abou Shafeey HE. Desportesius invaginatus (Linstow, 1901) Chabaud and Campana, 1949 (Nematoda, Acuariidae) from Ardeola ibis ibis with reference to the fine structure of the cordons. PUJ 2012;5(1): 4957.

4. Smith SA, Richards KS. Ultrastructure and microanalysis of the protoscolex hooks of Echinococcus granulosus. Parasitol 1991; 103: 267274.

5. Sávoly Z, Nagy P, HavancsákK, Záray G. Microanalytical investigation of nematodes. Microchem J 2012; 105: 83-87.

6. Martin RE, Donahue MJ. Tissue and ultrastructural localization of 5-hydroxytryptamine (serotonin) in the tissues of Ascaris suum with energy dispersive 
X-ray spectrometry of immunoreactive structures. Int J Parasitol 1989;19(6): 585-596.

7. Gianotti AJ, Clark DT, Dash J. Zinc sulfide in intestinal cell granules of Ancylostoma caninum adults. J Parasitol 1991;77(2): 285-289.

8. Millward RN. Intracellular inclusions in the nematode Tripyloides marinus from metal-enriched and cleaner estuaries in Cornwall, south-west England. J Mar Biol Assoc UK 1996; 76: 885-895.

9. Sures B. Accumulation of heavy metals by intestinal helminths in fish: an overview and perspective. Parasitol 2003; 126: 53-60.

10. Heckmann RA, Amin OM, Standing MD. Chemical analysis of metals in acanthocephalans using energy dispersive X-ray analysis (EDXA) in conjunction with a scanning electron microscope (SEM). Comp Parasitol 2007; 74: 388-391.

11. Tímea B, Larisa GP, Noemí RM, Vladimíra $H$. Ultrastructure and chemical composition of the proboscis hooks of Acanthocephalus lucii Müller, 1776 (Acanthocephala: Palaeacanthocephala) using X-ray elemental analysis. Folia Parasitol 2014;61(6): $549-557$.

12. Lee PE. Scanning Electron Microscopy and X-ray Microanalysis. Prentice Hall, Englewood Cliffs, New Jersey 1992; 458.

13. Heckmann RA, El Naggar A, Radwan NA, Standing MD. Fine structure and chemical analysis of Neoechinorhynchus idahooensis (Acanthocephala: Neoechinorhynchidae) in the Bridgelip sucker Catostomus columbianus. Proc Parasitol 2010; 50: 6371.

14. Radwan NA, AbouShafeey HE, Khalil AI. Chemical characterization of tegmental spines of four Digenean species using energy dispersive X-ray microanalysis (EDXA). Int J Parasitol Res 2012; 4(2): 100-105.

15. Heckmann RA, Amin OM, Radwan NA, Standing MD, Eggett DL. Comparative chemical element analysis using energy dispersive $\mathrm{X}$-ray microanalysis (EDXA) for four species of Acanthocephala. Sci Parasitol 2012a; 13: 27-35.

16. Heckmann RA, Amin OM, Radwan NA, Standing MD, Eggett DL, El Naggar AM. Fine structure and energy dispersive X-ray analysis (EDXA) of the proboscis hooks of Rhadinorhynchus ornatus Van Cleave, 1918 (Rhadinorhynchidae: Acanthocephala). Sci Parasitol 2012b; 13: 37-43.
17. Fraser RDB, Mac Rae TP, Rogers GE. Keratins, The Composition, Structure and Biosynthesis. Charles C Thomas Springfield 1972; Ill.

18. Galagher HC. Chemical composition of hook isolated from hydatid scolices. Exp Parasitol 1964; 15: 11001117.

19. Dvorack JA. Hymenolepis microstoma: Interference microscopy of embryonic lateral hooks. II. Structure and reaction to 2-mercaptoethanol. Exp Parasitol 1969b; 26: 101-110.

20. Pence DR. Electron microscope and histochemical studies on the egg of Hymenolepis diminuta. J Parasitol 1970; 56: 84-97.

21. Swiderski Z. Electron microscopy and histochemistry of onchospheral hook formation by the cestode Catenotaenia pussilla. Int J Parasitol 1973; 3: 27-33.

22. Holmes SD, Fairweather I. Hymenolepes diminuta: the mechanism of egg hatching. Parasitol 1982; 85: 237-250.

23. Kennedy E, Welch HE, Dick TA. Cordon and spine ultrastructure of the waterfowl parasite Echinuria uncinata (Rudolphi 1819) Soloviev 1912 (Spirurida: Nematoda). Can J Zool 1973; 51(11): 1133-1137.

24. Wong PL, Anderson RC. Revision of the genus Desportesius Chabaud and Campana, 1949 (Nematoda: Acuarioidea) mainly from the gizzard of ciconiform birds. Can J Zool 1986; 64: 2520-2530.

25. Mutafchiev Y, Georgiev BB. Redescription of Desportesius brevicaudatus (Spirurida, Acuariidae) based on nematodes from Ixobrychus minutus (Aves, Ciconiiformes) from Bulgaria. J Helminthol 2009; 46(2): 90-96.

26. Varjabedian KG. An ultrastructural study on Desportesius invaginatus (Nematoda, Acuariidae) from Ardeola ibis ibis in Egypt. J Egypt Soc Parasitol 2006; 36(1): 149-154.

27. Anderson RC, Chabaud AG, Willmott S. Spiruroidea, Habronematoidea and Acuarioidea by Alain G. Chabaud, 361-390. In: Anderson RC, Chabaud AG, Willmott S (Eds): Keys to the Nematode Parasites of Vertebrates, archival volume. 2009.

28. Vance DE, Ehmann WD, Markesbery WR. Trace element content in fingernails and hair of a nonindustrialized US control population. Biol Trace Elem Res 1988;17: 109-121. 
29. Robinson GR, Sibrell PL, Boughton CJ, Yang LH. Influence of soil chemistry on metal and bio-essential element concentrations in nymphal and adult periodical cicadas (Magicicada spp.). Sci Total Environ 2007; 374: $367-378$

30. Wilmot NV, Fallick AE. Original mineralogy of trilobite exoskeletons. Palaeontology 1989; 32(2): 297-304.

31. Ameh AO, Isa MT, Adeleye TJ, Adama KK. Kinetics of demineralization of shrimp exoskeleton in chitin and chitosan synthesis. J Chem Eng Mater Sci 2013; 4(3): $32-37$.

32. Nowicka W, Machoy Z, Gutowska I, Noceń I, Piotrowska S, Chlubek D. Contents of calcium, magnesium, and phosphorus in antlers and cranial bones of the European red deer (Cervus elaphus) from different regions in Western Poland. Pol J Environ Stud 2006; 15(2): 297-301.

33. Makanjuola OM. Chemical analysis of flesh and some body parts of different fresh fish in South West Nigeria. PJN 2012; 11(1): 14-15. 